\title{
Evaluation of Zoysiagrass Genotypes for Shade Tolerance
}

\author{
Bradley S. Sladek, Gerald M. Henry ${ }^{1}$, and Dick L. Auld \\ Department of Plant and Soil Science, Texas Tech University, \\ Box 42122, Lubbock, TX 79409
}

Additional index words. Zoysia japonica, Zoysia matrella, light intensity

\begin{abstract}
Establishing turfgrass in shaded environments can create a unique maintenance challenge. Shading reduces zoysiagrass (Zoysia spp.) photosynthesis and results in reduced turfgrass aesthetic quality. Zoysiagrass is a warm-season, perennial turfgrass that forms a dense, uniform turf through the production of rhizomes and stolons. It has demonstrated good tolerance to growth in reduced light intensity environments. Greenhouse experiments were conducted in 2006 and 2007 to evaluate the relative difference in growth response to three light intensities $(0 \%, 50 \%$, and $90 \%$ shade) among six zoysiagrass genotypes under artificial shade conditions. Percent change in zoysiagrass plug diameter decreased as shade level increased 6 and 12 weeks after planting (WAP) regardless of year or genotype. 'Diamond' and 'Shadow Turf' exhibited the greatest percent change in plug diameter 12 WAP $(60 \%$ to $69 \%)$ followed by the remaining zoysiagrass genotypes $(21 \%$ to $56 \%)$ when grown under $50 \%$ shade, regardless of year. In 2006, no zoysiagrass genotype maintained acceptable turfgrass quality (6 or greater) 12 WAP when grown under $\mathbf{5 0 \%}$ shade. However, 'Diamond' and 'Shadow Turf' exhibited acceptable turfgrass quality ratings (7.0 and 6.3) 12 WAP in 2007, whereas all other genotypes exhibited unacceptable turfgrass quality ratings (5.0 to 5.7). In 2006 , 'Shadow Turf' zoysiagrass exhibited the greatest percent increase in plug diameter $(21 \%)$ followed by 'DALZ 0501' (15\%) and 'Diamond' (5\%) 12 WAP when grown under $90 \%$ shade. All other zoysiagrass genotypes exhibited decreases in plug diameter (31\% to $87 \%)$. In 2007 , 'Shadow Turf' and 'Diamond' exhibited the greatest percent change in plug diameter (11\%) followed by 'DALZ 0501' (7\%) 12 WAP when grown under $90 \%$ shade. All other zoysiagrass genotypes exhibited decreases in plug diameter $(17 \%$ to $38 \%)$. Turfgrass quality declined as shade level increased 6 and 12 WAP regardless of year or genotype. 'Shadow Turf' and 'Diamond' exhibited the highest turfgrass quality ratings (4.7 and 3.7, respectively, in 2006 and 5.3 in 2007) 12 WAP when grown under 90\% shade. Proper zoysiagrass cultivar selection may improve turfgrass growth and quality under low light intensity while increasing turfgrass options for shaded environments.
\end{abstract}

Establishing turfgrass in shaded environments can create a unique maintenance challenge. Approximately $20 \%$ to $25 \%$ of all turfgrasses are grown in low light intensity environments (Beard, 1973). Reductions in light intensity may decrease the photosynthetic capacity of turfgrasses and lead to the depletion of carbohydrate reserves (Schmidt and Blaser, 1967; Winstead and Ward, 1974). Changes in physiological characteristics may alter zoysiagrass (Zoysia spp.) morphology and result in reductions in turfgrass aesthetic quality. Turfgrasses grown in shade may exhibit reduced leaf and stem width, increased leaf length and plant height, reduced shoot

Received for publication on 5 Mar. 2009. Accepted for publication on 8 June 2009.

Texas Tech University manuscript no. T-4-598. We acknowledge the cooperation of Justin Weeaks, Nick Sanford, and Aaron Holbrook for their technical assistance on this project. Appreciation is also extended to Mark Ivey for providing 'Shadow Turf' zoysiagrass germplasm. Additional thanks are extended to Dr. Milt Engelke for providing 'DALZ 0501', 'Diamond', and 'Zorro' zoysiagrass germplasm.

${ }^{1}$ To whom reprint requests should be addressed; e-mail gerald.henry@ttu.edu. density, longer internodes, reduced tillering, and a more upright growth habit (Beard, 1973; Dudeck and Peacock, 1992; McBee and Holt, 1966; Peacock and Dudeck, 1981; Wherley et al., 2005; Wilkinson and Beard, 1974; Winstead and Ward, 1974). Previous research has reported reductions in turfgrass quality and growth rate of several turfgrass species grown under reduced light intensity environments (Barrios et al., 1986; Beard, 1965; Jiang et al., 2004; McBee and Holt, 1966; Peacock and Dudeck, 1981; Tegg and Lane, 2004).

Zoysiagrass has demonstrated good tolerance to reduced light intensities (Morton et al., 1991; Qian and Engelke, 1999a; Qian et al., 1998). It is a warm-season, perennial turfgrass native to parts of China, Japan, and Korea (Engelke and Anderson, 2003). Zoysiagrass is adapted throughout the southern humid region of the United States to the northern transition zone. It forms a dense, uniform turf through the production and spread of rhizomes and stolons (Turgeon, 2008). Zoysiagrass is predominantly used on golf courses, athletic fields, residential lawns, and commercial landscapes. Adaptation to a wide range of environmental conditions has further led to an increase in zoysiagrass popularity. Zoysiagrass tolerates moderate salinity levels (Marcum et al., 1998; Qian et al., 2000), moderate drought conditions (Qian and Engelke, 1999b; White et al., 2001), and exposure to low temperatures (Dunn et al., 1999; Patton and Reicher, 2007; Warmund et al., 1998). Extensive documentation exists on the tolerance of 'Diamond' zoysiagrass to shaded environments (Engelke et al., 2002; Qian and Engelke, 1999a, 1999c; Qian et al., 1998). Acceptable turfgrass quality (6 or greater) was maintained by 'Diamond' zoysiagrass when subjected to $81 \%$ or less shade for 6 weeks (Qian and Engelke, 1999a). However, a wide range of relative shade tolerance exists between turfgrass species (Barrios et al., 1986; McBee and Holt, 1966; Morton et al., 1991; Qian and Engelke, 1999a, 1999c; Qian et al., 1998; Tegg and Lane, 2004; Winstead and Ward, 1974).

Evaluating the response of multiple zoysiagrass genotypes grown in shade may provide additional information on the ability of these grasses to tolerate reduced light environments. Further identification of shadetolerant genotypes may provide turfgrass managers with additional options for shaded environments. Therefore, the objective of this research was to evaluate the relative difference in growth response to three light intensities among six zoysiagrass genotypes under artificial shade conditions.

\section{Materials and Methods}

Experiments were conducted in 2006 and 2007 at the Texas Tech University Horticulture Greenhouse in Lubbock, TX. Plugs measuring $2.5 \mathrm{~cm}^{2}$ of six zoysiagrass genotypes [Zoysia japonica Steud. genotype ('Meyer'); Z. matrella (L.) Merr genotypes ('Shadow Turf', 'Diamond', 'DALZ 0501', and 'Zorro'); and Z. japonica $\times$ Z. pacifica Goudsw. genotype ('Emerald')] were vegetatively propagated by stem cuttings in potting medium containing $55 \%$ bark, $20 \%$ Canadian sphagnum peatmoss, $10 \%$ pearlite, $15 \%$ vermiculite, dolomitic lime, gypsum, and a wetting agent (Sun Gro Horticulture, Vancouver, British Columbia, Canada). One plug of each genotype was transplanted into 3.8-L plastic pots using the same potting media previously described. Fertilizer $(16 \mathrm{~N}-$ 10.5P-9.9K) (The Andersons, Inc., Maumee, $\mathrm{OH})$ was applied at the time of transplant at a rate of $24.4 \mathrm{~kg} \cdot \mathrm{ha}^{-1}$ nitrogen. Fertility was withheld for the duration of the trial. After transplanting, plugs were heavily irrigated to saturate the media and allowed to acclimate in full sunlight for 1 week before initiation of the shade treatments. Shade treatments consisted of $0 \%$ (control), $50 \%$, and $90 \%$ shade. Shade levels were selected to represent moderate $(50 \%)$ and heavy $(90 \%)$ shade conditions and are percent reductions in light intensity from average midday (1200 and $1300 \mathrm{HR}$ ) solar radiation (636 to 754 $\left.\mu \mathrm{mol} \cdot \mathrm{m}^{-2} \cdot \mathrm{s}^{-1}\right)$ present in the greenhouse during the length of this trial. Shade treatments were imposed using black, mesh, knitted shadecloth (DeWitt Knitted Shadecloth; 
DeWitt Co., Sikeston, MO) secured to polyvinyl chloride frames measuring $78 \times 85 \times 51$ $\mathrm{cm}$. A spectrophotometer was used to control manufacturer specifications of each shadecloth. Shade canopies were secured to the greenhouse bench for the duration of the experiment. One pot of each genotype was placed under each light intensity on 19 Dec. 2006 and 5 Dec. 2007. Pots were arranged in a $3 \times 6$ factorial arranged in a split plot design with three replications to evaluate shade level (main plot) and genotype (subplot within shade level). Plants were mowed every 2 weeks and maintained at a height of $1.9 \mathrm{~cm}$ with a set of handheld, electric grass shears (Oster Showmaster; Jarden Corporation, Rye, NY). Irrigation was applied daily for the first week to encourage plug rooting and as needed for the remainder of the trial. Plants were removed from shade canopies for $\approx 1 \mathrm{~h} /$ week to record data or mow plants. Natural light was supplemented with artificial light at $500 \mu \mathrm{mol} \cdot \mathrm{m}^{-2} \cdot \mathrm{s}^{-1}$ photosynthetic photon flux in a 12-h day to approximate summer light intensity and photoperiod. Conditions in the greenhouse were maintained at day/night temperatures of $34 / 26^{\circ} \mathrm{C}$.

Lateral plant diameters were taken at the beginning of each study and were recorded every 2 weeks for a total of 12 weeks. Two diameter measurements were taken perpendicular to each other and averaged to obtain the reported diameter of each plant at each sampling time. Maximum plug diameter was obtained when plugs grew to the edge of the pot. Bimonthly plug diameter measurements were converted to percent plug diameter increase by comparison with initial plug diameters. Percent zoysiagrass cover was visually estimated for each pot bimonthly for the duration of the experiment on a scale of $0 \%$ (no cover) to $100 \%$ (complete turfgrass cover). Turfgrass cover was further quantified using digital image analysis to ensure accuracy of visual ratings. Turfgrass quality was visually estimated for each pot bimonthly for 12 weeks on a scale of 1 to 9 with 9 representing ideal dark green, uniform turf; 6 representing minimally acceptable turf; and 1 representing dead turf.

All data were subjected to analysis of variance (ANOVA) using error partitioning appropriate to a split plot analysis in the general linear models procedure provided by SAS (SAS Inc., Cary, NC). Data were pooled across years to test for significant year interactions. The arcsine square root transformations of percent change in plug diameter, percent zoysiagrass cover, and turfgrass quality were also subjected to ANOVA but were not different from nontransformed data; therefore, nontransformed data are presented. Means were separated using Fisher's protected least significant difference test at the 0.05 probability level.

\section{Results}

Analysis of variance revealed a significant genotype by year $(P<0.0001)$ interaction; therefore, data for 2006 and 2007 are presented separately. Significant main plot effects of shade level $(P<0.0001)$ and subplot effects of zoysiagrass genotype $(P<$ $0.0001)$ were observed for all data in 2006 and 2007. A significant shade level by zoysiagrass genotype $(P<0.0001)$ interaction was also observed for all data in both years.

Percent change in plug diameter and percent zoysiagrass cover resulted in nearly identical values; thus, only percent change in plug diameters, along with turfgrass quality are presented. Percent change in zoysiagrass plug diameter decreased with increasing shade level 6 weeks after planting (WAP) regardless of year or genotype. In 2006, percent change in zoysiagrass plug diameter ranged from $47 \%$ to $68 \% 6 \mathrm{WAP}$ in $0 \%$ shade regardless of genotype (Table 1). Percent change in plug diameter 6 WAP of zoysiagrass plants subjected to $50 \%$ shade ranged from $19 \%$ to $38 \%$ across all genotypes. 'Shadow Turf', 'Diamond', 'DALZ 0501', and 'Emerald' exhibited increases in plug diameter of $17 \%$ to $18 \% 6$ WAP when grown under 90\% shade. 'Zorro' and 'Meyer' exhibited a decrease in plug diameter of $38 \%$ and $49 \%$, respectively, 6 WAP when grown under $90 \%$ shade.

In 2007, percent change in zoysiagrass plug diameter ranged from $32 \%$ to $74 \% 6$ WAP when grown under $0 \%$ shade regardless of genotype (Table 1). Percent change in plug diameter 6 WAP when zoysiagrass was grown under $50 \%$ shade ranged from $16 \%$ to $41 \%$ regardless of genotype. 'DALZ 0501' exhibited the largest percent change in plug diameter (14\%) followed by 'Shadow Turf' (10\%), 'Diamond' (10\%), and 'Meyer' (6\%) 6 WAP when subjected to $90 \%$ shade. 'Emerald' and 'Zorro' zoysiagrass exhibited decreases in plug diameter of $2 \%$ and $3 \%$, respectively, 6 WAP when grown under $90 \%$ shade.

Percent change in zoysiagrass plug diameter decreased with increasing shade level 12 WAP regardless of year or genotype. In 2006, 'Diamond' exhibited the greatest percent change in plug diameter (124\%) followed by 'Meyer' (103\%) 12 WAP when grown under $0 \%$ shade (Table 2). The remaining zoysiagrass genotypes exhibited percent changes in plug diameter of $53 \%$ to $88 \%$ 12 WAP. 'Diamond' and 'Shadow Turf' exhibited the greatest percent changes in plug diameter (69\% and $68 \%$, respectively) 12 WAP when grown under $50 \%$ shade. Percent changes in plug diameter of the remaining zoysiagrass genotypes ranged from $28 \%$ to $56 \%$. 'Shadow Turf' zoysiagrass exhibited the greatest percent change in plug diameter (21\%) followed by 'DALZ 0501' (15\%) and 'Diamond' (5\%) 12 WAP when grown under $90 \%$ shade. The remaining zoysiagrass genotypes exhibited decreases in plug diameter of $31 \%$ to $87 \%$.

In 2007, 'Shadow Turf' and 'DALZ 0501' exhibited the greatest percent change in plug diameter (114\% and $107 \%$, respectively) followed by the remaining zoysiagrass genotypes ( $72 \%$ to $91 \%) 12$ WAP when grown under $0 \%$ shade (Table 2 ). 'Shadow Turf' and 'Diamond' exhibited the greatest percent change in plug diameter $(60 \%)$ followed by 'Emerald' (49\%), 'DALZ 0501' (48\%), 'Meyer' (24\%), and 'Zorro' (21\%) 12 WAP when subjected to $50 \%$ shade. 'Shadow Turf' and 'Diamond' exhibited the greatest percent change in plug diameter (11\%) followed by 'DALZ 0501' (7\%) 12 WAP when grown under $90 \%$ shade. The remaining zoysiagrass genotypes exhibited decreases in plug diameter of $17 \%$ to $38 \%$.

Turfgrass quality declined as shade level increased 6 WAP regardless of year or genotype. In 2006, 'Diamond' typically exhibited the highest turfgrass quality ratings (5.7 to 7.7) 6 WAP regardless of shade level (Table $3)$. All other zoysiagrass genotypes maintained acceptable turfgrass quality (6 or greater) $6 \mathrm{WAP}$ when grown under $0 \%$ shade, except 'Zorro', which received a rating of 5.3 in 2006. 'Shadow Turf' and 'Diamond' exhibited the highest turfgrass quality (6.3 and 6.0 , respectively) 6 WAP when grown under $50 \%$ shade. The remaining zoysiagrass genotypes exhibited turfgrass quality ratings that were less than acceptable when grown under $50 \%$ shade. No zoysiagrass genotype exhibited acceptable turfgrass quality 6 WAP under $90 \%$ shade. 'Diamond' exhibited the highest turfgrass quality (5.7) 6 WAP when grown under $90 \%$ shade followed by 'Shadow Turf' (5.3). The remaining zoysiagrass genotypes exhibited turfgrass quality ratings of 1.7 to 3.7 .

In 2007, 'Diamond' received the highest turfgrass quality ratings (6.0 to 7.7) 6 WAP regardless of shade treatment (Table 3). 'Shadow Turf' and 'DALZ 0501' exhibited turfgrass quality ratings of 7.36 WAP when subjected to $0 \%$ shade. The remaining zoysiagrass genotypes also received acceptable turfgrass quality ratings of 6.3 to 7.0. 'Diamond' and 'Shadow Turf' exhibited the highest turfgrass quality (7.0) 6 WAP when grown under $50 \%$ shade followed by 'Emerald' (6.7). 'Meyer' was the only zoysiagrass genotype that received an unacceptable turfgrass quality rating (5.7) $6 \mathrm{WAP}$ when grown under $50 \%$ shade. 'Diamond' exhibited the highest turfgrass quality (6.0) 6 WAP when grown under $90 \%$ shade. All other zoysiagrass genotypes received unacceptable turfgrass quality ratings (4.7 to 5.7).

Turfgrass quality declined as shade level increased 12 WAP regardless of year or genotype. In 2006, 'Shadow Turf' exhibited the greatest turfgrass quality ( 4.7 to 7.0$) 12$ WAP regardless of shade treatment (Table 4). All zoysiagrass genotypes maintained acceptable turfgrass quality (6.3 to 7.0$) 12$ WAP when grown under $0 \%$ shade, except for 'Zorro' (5.7). 'Shadow Turf' exhibited the highest turfgrass quality (5.7) 12 WAP when subjected to $50 \%$ shade followed by 'Diamond' (5.0), 'Zorro' (5.0), and 'Meyer' (5.0). No zoysiagrass genotype exhibited acceptable turfgrass quality 12 WAP when grown under $90 \%$ shade. 'Shadow Turf' and 'Diamond' exhibited the highest turfgrass quality (4.7 and 3.7, respectively). The remaining zoysiagrass genotypes exhibited turfgrass quality ratings of 1.0 to 1.7 . 
Table 1. Percent change in plug diameter of six zoysiagrass genotypes when exposed to $0 \%, 50 \%$, and $90 \%$ shade 6 WAP.

\begin{tabular}{|c|c|c|c|c|c|c|}
\hline \multirow[b]{4}{*}{ Genotype } & \multicolumn{6}{|c|}{ Plug diam. change 6 WAP } \\
\hline & \multicolumn{3}{|c|}{2006 shade level } & \multicolumn{3}{|c|}{2007 shade level } \\
\hline & 0 & 50 & 90 & 0 & 50 & 90 \\
\hline & \multicolumn{6}{|c|}{$(\%)$} \\
\hline$\overline{\text { DALZ } 0501^{z}}$ & 49 & 21 & 17 & 64 & 29 & 14 \\
\hline Diamond & 52 & 38 & 18 & 52 & 41 & 10 \\
\hline Emerald & 68 & 19 & 17 & 47 & 29 & -2 \\
\hline Meyer & 55 & 33 & -49 & 49 & 24 & 6 \\
\hline Shadow Turf & 68 & 36 & 18 & 74 & 40 & 10 \\
\hline Zorro & 47 & 34 & -38 & 32 & 16 & -3 \\
\hline Least significant difference $(0.05)$ & $\mathrm{NS}^{\mathrm{y}}$ & NS & 48 & 22 & NS & 10 \\
\hline
\end{tabular}

${ }^{2}$ Cultivars are listed alphabetically.

${ }^{y_{N S}}=$ no significant differences between plug diameter increases among genotypes during this year at this shade level.

$\mathrm{WAP}=$ weeks after planting.

Table 2. Percent change in plug diameter of six zoysiagrass genotypes when exposed to $0 \%, 50 \%$, and $90 \%$ shade 12 WAP.

\begin{tabular}{|c|c|c|c|c|c|c|}
\hline \multirow[b]{4}{*}{ Genotype } & \multicolumn{6}{|c|}{ Plug diam. change 12 WAP } \\
\hline & \multicolumn{3}{|c|}{2006 shade level } & \multicolumn{3}{|c|}{2007 shade level } \\
\hline & 0 & 50 & 90 & 0 & 50 & 90 \\
\hline & \multicolumn{6}{|c|}{$(\%)$} \\
\hline$\overline{\mathrm{DALZ} 0501^{\mathrm{z}}}$ & 84 & 37 & 15 & 107 & 48 & 7 \\
\hline Diamond & 124 & 69 & 5 & 89 & 60 & 11 \\
\hline Emerald & 78 & 28 & -31 & 91 & 49 & -21 \\
\hline Meyer & 103 & 56 & -87 & 72 & 24 & -17 \\
\hline Shadow Turf & 88 & 68 & 21 & 114 & 60 & 11 \\
\hline Zorro & 53 & 40 & -55 & 79 & 21 & -38 \\
\hline Least significant difference $(0.05)$ & 40 & 24 & 42 & 23 & 24 & 35 \\
\hline
\end{tabular}

${ }^{\mathrm{z}}$ Cultivars are listed alphabetically.

$\mathrm{WAP}=$ weeks after planting.

Table 3. Turfgrass quality (TQ) of six zoysiagrass genotypes when exposed to $0 \%, 50 \%$, and $90 \%$ shade 6 WAP.

\begin{tabular}{|c|c|c|c|c|c|c|}
\hline \multirow[b]{4}{*}{ Genotype } & \multicolumn{6}{|c|}{ Turfgrass quality $6 \mathrm{WAP}$} \\
\hline & \multicolumn{3}{|c|}{2006 shade level } & \multicolumn{3}{|c|}{2007 shade level } \\
\hline & 0 & 50 & 90 & 0 & 50 & 90 \\
\hline & \multicolumn{6}{|c|}{ TQ (1-9) } \\
\hline$\overline{\text { DALZ } 0501^{z}}$ & 6.7 & 4.3 & 3.3 & 7.3 & 6.0 & 5.7 \\
\hline Diamond & 7.7 & 6.0 & 5.7 & 7.7 & 7.0 & 6.0 \\
\hline Emerald & 6.3 & 5.3 & 3.7 & 7.0 & 6.7 & 5.7 \\
\hline Meyer & 7.0 & 5.3 & 1.7 & 6.3 & 5.7 & 5.3 \\
\hline Shadow Turf & 7.0 & 6.3 & 5.3 & 7.3 & 7.0 & 5.3 \\
\hline Zorro & 5.3 & 5.3 & 1.7 & 6.3 & 6.0 & 4.7 \\
\hline Least significant difference $(0.05)$ & 0.9 & 1.1 & 1.6 & 0.6 & 0.6 & 1.0 \\
\hline
\end{tabular}

${ }^{\mathrm{z}}$ Cultivars are listed alphabetically.

$\mathrm{WAP}=$ weeks after planting.

Table 4. Turfgrass quality (TQ) of six zoysiagrass genotypes when exposed to $0 \%, 50 \%$, and $90 \%$ shade 12 WAP.

\begin{tabular}{|c|c|c|c|c|c|c|}
\hline \multirow[b]{4}{*}{ Genotype } & \multicolumn{6}{|c|}{ Turfgrass quality $12 \mathrm{WAP}$} \\
\hline & \multicolumn{3}{|c|}{2006 shade level } & \multicolumn{3}{|c|}{2007 shade level } \\
\hline & 0 & 50 & 90 & 0 & 50 & 90 \\
\hline & \multicolumn{6}{|c|}{ TQ (1-9) } \\
\hline$\overline{\text { DALZ } 0501^{z}}$ & 6.7 & 4.3 & 1.7 & 7.0 & 5.0 & 4.7 \\
\hline Diamond & 7.0 & 5.0 & 3.7 & 7.0 & 7.0 & 5.3 \\
\hline Emerald & 6.7 & 4.3 & 1.7 & 5.7 & 5.3 & 3.0 \\
\hline Meyer & 6.3 & 5.0 & 1.0 & 6.0 & 5.0 & 2.3 \\
\hline Shadow Turf & 7.0 & 5.7 & 4.7 & 7.0 & 6.3 & 5.3 \\
\hline Zorro & 5.7 & 5.0 & 1.3 & 6.0 & 5.3 & 2.0 \\
\hline Least significant difference $(0.05)$ & 0.8 & $\mathrm{NS}^{\mathrm{y}}$ & 1.4 & 0.4 & 1.0 & 2.0 \\
\hline
\end{tabular}

${ }^{\mathrm{z}}$ Cultivars are listed alphabetically.

${ }^{y_{N S}}=$ no significant differences between turfgrass quality among genotypes during this year at this shade level.

$\mathrm{WAP}=$ weeks after planting.
In 2007, 'Diamond' exhibited the highest turfgrass quality (5.3 to 7.0) 12 WAP regardless of shade treatment (Table 4). Turfgrass quality of zoysiagrass genotypes ranged from 5.7 to 7.012 WAP when grown under $0 \%$ shade. 'Diamond' and 'Shadow Turf' exhibited the highest turfgrass quality $(7.0$ and 6.3 , respectively) $12 \mathrm{WAP}$ when grown under $50 \%$ shade with all other genotypes expressing quality ratings of 5.0 to 5.3. No zoysiagrass genotype exhibited acceptable turfgrass quality 12 WAP when grown under 90\% shade in 2007. 'Diamond' and 'Shadow Turf' exhibited the highest turfgrass quality (5.3). The remaining zoysiagrass genotypes exhibited turfgrass quality ratings of 2.0 to 4.7 .

\section{Discussion}

These results indicate that differences were observed in the growth responses among six zoysiagrass genotypes subjected to the experimental conditions previously described. The light intensity in which these plants were evaluated was considerably reduced compared with ambient light conditions typically observed during summer months. However, variability was observed among the zoysiagrass genotypes in response to reduced light intensity. As an implication, the results of this experiment need to be evaluated under more practical field research conditions. However, this research does serve to identify and estimate the relative responses of these six zoysiagrass genotypes when grown under reduced light conditions.

Zoysiagrass growth and establishment differed by genotype when subjected to full sun conditions. In 2006, 'Diamond', 'Meyer', and 'Shadow Turf' zoysiagrass exhibited the greatest increase in plug diameter, whereas 'Shadow Turf', 'DALZ 0501', and 'Emerald' exhibited the greatest increase in plug diameter in 2007. Year-to-year differences may be explained by greenhouse light intensity. Light intensity values were similar for the first 6 weeks of each trial in 2006 and 2007. However, in 2007, average midday solar radiation between 7 and 12 WAP was $\approx 50 \%$ greater $\left(998 \mu \mathrm{mol} \cdot \mathrm{m}^{-2} \cdot \mathrm{s}^{-1}\right)$ than $2006(654$ $\left.\mu \mathrm{mol} \cdot \mathrm{m}^{-2} \cdot \mathrm{s}^{-1}\right)$. Increased light intensity during the last 6 weeks of the trial in 2007 may have enhanced the growth of certain zoysiagrass genotypes and resulted in differences in the outcome of each study.

Several other research projects have examined the growth of zoysiagrass in full sun conditions. Karcher et al. (2005) reported zoysiagrass divot recovery of 'Zorro' > 'Emerald' > 'Meyer' when grown in full sun. Patton et al. (2007) observed zoysiagrass establishment rates of 'Zorro' > 'Meyer' > 'Emerald' $>$ 'Diamond' when subjected to full sun. 'Zorro' exhibited the slowest establishment in our research in 2006 and second slowest in 2007. Differences in zoysiagrass genotype establishment under full sun conditions may be explained by the growth environment, fertility practices, and plant age used in each trial. Karcher et al. (2005) and Patton et al. (2007) conducted zoysiagrass 
establishment on native soil in the field, whereas our research was conducted in the greenhouse using soilless potting media. Karcher et al. (2005) provided monthly fertility applications, whereas Patton et al. (2007) applied fertility twice during the growing season at $49 \mathrm{~kg} \cdot \mathrm{ha}^{-1}$ nitrogen. Fertility was only applied at the initiation of our trial at a rate of $24.4 \mathrm{~kg} \cdot \mathrm{ha}^{-1}$ nitrogen. Additional fertility applications throughout the length of the trial may have enhanced zoysiagrass growth. Zoysiagrass used by Karcher et al. (2005) was over 1 year old, whereas plants examined in our research were more juvenile. The higher photosynthetic capability of sod compared with plugs may have increased shade tolerance and plant survival.

Subjecting zoysiagrass plugs to shade caused reductions in growth and turfgrass quality regardless of year or genotype. Reductions were amplified as shade level increased. However, zoysiagrass genotypes did respond differently to shade levels. Smaller increases in plug growth were observed for plants grown under $50 \%$ shade when compared with the control. In contrast, McBee and Holt (1966) observed an increase in 'Meyer' zoysiagrass cover when exposed to $40 \%$ and $65 \%$ shade. However, shade treatments in this research were implemented with one-sided shadecloth canopies, which may have allowed ambient light penetration and increased photosynthetic opportunities. Reductions in turfgrass quality compared with the control were also evident in zoysiagrass plants subjected to $50 \%$ shade. In our research, 'Diamond' zoysiagrass exhibited turfgrass quality ratings of 5.0 and 7.012 WAP in 2006 and 2007, respectively, when subjected to $50 \%$ shade. In contrast, Qian and Engelke (1999a) reported turfgrass quality ratings 8 or greater for 'Diamond' zoysiagrass grown under $47 \%$ shade for 22 weeks. However, this research was conducted on fully established, mature zoysiagrass sod, whereas our research focused on the growth of zoysiagrass from plugs. The higher photosynthetic capability of sod compared with plugs may have increased shade tolerance and plant survival. Barrios et al. (1986) reported a turfgrass quality rating of 5.7 for 'Emerald' zoysiagrass when subjected to $47 \%$ shade for 3 years. In our research, 'Emerald' zoysiagrass received turfgrass quality ratings of 4.3 and 5.3 12 WAP in 2006 and 2007, respectively, when grown under $50 \%$ shade.

The greatest impact on growth and turfgrass quality was observed on zoysiagrass plugs subjected to $90 \%$ shade. Small increases in plug growth were observed in 'Shadow Turf', 'Diamond', and 'DALZ 0501', whereas large decreases in growth were observed in 'Emerald', 'Zorro', and 'Meyer' 12 WAP. Turfgrass quality was reduced below acceptable standards (less than 6.0) for all genotypes when compared with the control 12 WAP. In our research, 'Diamond' exhibited the highest turfgrass quality rating (5.3) in 2006 and second high- est (3.7) in 2007. In contrast, Qian et al. (1998) reported that 'Diamond' zoysiagrass exhibited a turfgrass quality rating of 7.512 WAP when subjected to $88 \%$ shade. Similarly, Qian and Engelke (1999a) reported that 'Diamond' zoysiagrass maintained a turfgrass quality rating of 6.9 when grown under $81 \%$ shade. Again, this research was conducted on mature zoysiagrass sod, which may have increased the ability of 'Diamond' to tolerate shade. Ervin et al. (2002) reported a turfgrass quality rating of 4.3 for 'Meyer' zoysiagrass when grown under $89 \%$ shade. In our research, turfgrass quality ratings of 'Meyer' were 1.0 and 2.3 12 WAP in 2006 and 2007, respectively, when subjected to 90\% shade. Similarly, Riffell et al. (1995) observed turf quality ratings on 'Meyer' of 1.5 to 2.0 at the end of the growing season. Ervin et al. (2002) conducted their research on a mature 'Meyer' fairway, potentially contributing to its higher turfgrass quality ratings. Although minimal research has been conducted on the $Z$. matrella genotypes 'Shadow Turf' and 'DALZ 0501', turfgrass quality and growth were similar to 'Diamond' grown under $50 \%$ and $90 \%$ shade.

Experiments were conducted during the winter of 2006 and 2007 when solar radiation was at its lowest. Average midday (1200 and $1300 \mathrm{HR}$ ) solar radiation obtained from full sun treatments ranged from 636 to 754 $\mu \mathrm{mol} \cdot \mathrm{m}^{-2} \cdot \mathrm{s}^{-1}$. This was considerably lower than the average midday solar radiation for summer months at our trial location (2753 $\left.\mu \mathrm{mol} \cdot \mathrm{m}^{-2} \cdot \mathrm{s}^{-1}\right)$. Although supplemental lighting was used in our experiments, it was not equivalent to summer growing conditions. Conducting research during summer months and/or providing more supplemental lighting may have resulted in higher turfgrass growth rates and quality.

Results suggest that differences exist between zoysiagrass genotypes with respect to shade tolerance. Establishing zoysiagrass from plugs in $50 \%$ shade remains feasible through the use of several improved genotypes. 'Shadow Turf' and 'Diamond' exhibited acceptable increases in lateral spread and moderate turf quality 12 WAP. However, performance of zoysiagrass genotypes subjected to $90 \%$ shade was poor, providing minimal turfgrass cover and aesthetic quality. Proper zoysiagrass cultivar selection may improve turfgrass growth and quality under low light intensity while increasing turfgrass options for difficult to manage environments.

\section{Literature Cited}

Barrios, G.W., F.J. Sundstrom, D. Babcock, and L. Leger. 1986. Quality and yield response of four warm-season lawngrasses to shade. Agron. J. $78: 270-273$

Beard, J.B. 1965. Factors in the adaptation of turfgrasses to shade. Agron. J. 57:457-459.

Beard, J.B. 1973. Turfgrass: Science and culture. Prentice-Hall, Englewood Cliffs, NJ.

Dudeck, A.E. and C.H. Peacock. 1992. Shade and turfgrass culture, p. 269-284. In: Waddingtion, D.V., R.N. Carrow, and R.C. Sherman (eds.). Turfgrass. Agron. Monogr. 32.
Dunn, J.H., S.S. Bughrara, M.R. Warmund, and B.F. Fresenburg. 1999. Low temperature tolerance of zoysiagrasses. HortScience 34:96-99.

Engelke, M.C. and S. Anderson. 2003. Zoysiagrasses (Zoysia spp.), p. 271-286. In: Casler, M.D. and R.R. Duncan (eds.). Turfgrass biology, genetics, and breeding. Wiley, Hoboken, NJ.

Engelke, M.C., P.F. Colbaugh, J.A. Reinert, K.B. Marcum, R.H. White, B. Rummele, and S.J. Anderson. 2002. Registration of 'Diamond' zoysiagrass. Crop Sci. 42:304-305.

Ervin, E.H., C.H. Ok, B.S. Fresenburg, and J.H. Dunn. 2002. Trinexapac-ethyl restricts shoot growth and prolongs stand density of 'Meyer' zoysiagrass fairway under shade. HortScience 37:502-505

Jiang, Y., R.R. Duncan, and R.N. Carrow. 2004. Assessment of low light tolerance of seashore paspalum and bermudagrass. Crop Sci. 44:587-594.

Karcher, D.E., M.D. Richardson, J.W. Landreth, and J.H. McCalla, Jr. 2005. Recovery of zoysiagrass varieties from divot injury. Online. Applied Turfgrass Science. 15 Mar. 2009. $<$ http://www.plantmanagementnetwork.org/ sub/ats/research/2005/zoysia/divotinjury.pdf>.

Marcum, K.B., S.J. Anderson, and M.C. Engelke. 1998. Salt gland ion secretion: A salinity tolerance mechanism among five zoysiagrass species. Crop Sci. 38:806-810.

McBee, G.G. and E.C. Holt. 1966. Shade tolerance studies on bermudagrass and other turfgrasses. Agron. J. 58:523-525.

Morton, S.J., M.C. Engelke, and R.H. White. 1991. Performance of four warm-season turfgrass genera cultured in dense shade. III. Zosyia spp. Texas Agr. Expt. Sta. PR-4894:51-52.

Patton, A.J. and Z.J. Reicher. 2007. Zoysiagrass species and genotypes differ in their winter injury and freeze tolerance. Crop Sci. 47:1619-1627.

Patton, A.J., J.J. Volenec, and Z.J. Reicher. 2007. Stolon growth and dry matter partitioning explains differences in zoysiagrass establishment rates. Crop Sci. 47:1237-1245.

Peacock, C.H. and A.E. Dudeck. 1981. The effects of shade on morphological and physiological parameter of st. augustinegrass cultivars. Proc of the Intl. Turfgrass Res. Conf. 4:493-500.

Qian, Y.L. and M.C. Engelke. 1999a. 'Diamond' zoysiagrass as affected by light intensity. J. of Turfgrass Mgt. 3:1-13.

Qian, Y.L. and M.C. Engelke. 1999b. Performance of five turfgrasses under linear gradient irrigation. HortScience 34:893-896.

Qian, Y.L. and M.C. Engelke. 1999c. Influence of trinexapac-ethyl on Diamond zoysiagrass in a shade environment. Crop Sci. 39:202-208.

Qian, Y.L., M.C. Engelke, and M.J.V. Foster. 2000. Salinity effects on zoysiagrass cultivars and experimental lines. Crop Sci. 40:488-492.

Qian, Y.L., M.C. Engelke, M.J.V. Foster, and S. Reynolds. 1998. Trinexapac-ethyl restricts shoot growth and improves quality of 'Diamond' zoysiagrass under shade. HortScience 33:1019-1022.

Riffell, S.K., M.C. Engelke, and S.J. Morton. 1995. Performance of three warm- season turfgrasses cultured in shade: Zoysiagrass. Tex. Turfgrass Res., p. 60-65.

Schmidt, R.E. and R.E. Blaser. 1967. Effect of temperature, light, and nitrogen on growth and metabolism of 'Cohansey' bentgrass (Agrostis palustrus Huds.). Crop Sci. 7:447-451.

Tegg, R.S. and P.A. Lane. 2004. A comparison of the performance and growth of a range of turfgrass species under shade. Aust. J. Agr. Res. 44:353-358. 
Turgeon, A.J. 2008. Turfgrass management. 8th Ed. Prentice Hall, Upper Saddle River, NJ.

Warmund, M.R., R. Fuller, and J.H. Dunn. 1998. Survival and recovery of 'Meyer' zoysiagrass rhizomes after extracellular freezing. J. Amer. Soc. Hort. Sci. 123:821-825.

Wherley, B.G., D.S. Gardner, and J.D. Metzger. 2005. Tall fescue photomorphogenesis as influ- enced by changes in spectral composition and light intensity. Crop Sci. 45:562-568.

White, R.H., M.C. Engelke, S.J. Anderson, B.A. Ruemmele, K.B. Marcum, and G.R. Taylor, II. 2001. Zoysiagrass water relations. Crop Sci. 41:133-138.

Wilkinson, J.F. and J.B. Beard. 1974. Morphological responses of Poa pratensis and Festuca rubra to reduced light intensity. In: Roberts, E.C. (ed.). Proc. 2nd Intl. Turfgrass Res. Conf. 2:231-240.

Winstead, C.W. and C.Y. Ward. 1974. Persistence of southern turfgrasses in a shade environment. In: Roberts, E.C. (ed.). Proc. of the 2nd Intl. Turfgrass Res. Conf. 2:221230 . 